\title{
MONITORING AND REMOVAL OF ACRYLAMIDE FROM AQUEOUS SOLUTION USING POTASSIUM PERMANGANATE
}

Abd El. Razek, T. M. ${ }^{(1)}$; Elsayed, Hanaa, H. ${ }^{(2)}$ and Zaghloul, E. E. ${ }^{(3)}$ 1) Institute of Environmental Studies \& Research, Ain Shams University. 2) National Nutrition Institute 3) Holding Company for Water and Wastewater

\begin{abstract}
Acrylamide is a probable carcinogen and has also been shown to be a neurotoxic agent in animals and humans. This work aims at removing acrylamide from aqueous solution using potassium permanganate. Several jar tests were carried out to investigate the effect of experimental parameters including initial solution $\mathrm{pH}$, dose and contact time upon the removal process. Data revealed a good percentage of acrylamide removal by potassium permanganate from $13.40 \%$ to $41.40 \%$ by increasing the dose from $0 . r$ to $1 \mathrm{ppm}$, respectively in neutral medium and from $r 9,0$ r\% to $96.67 \%$ in acidic medium. While in basic medium absence of acrylamide due to hydrolysis transformation into acrylic acid. On the other hand, results indicate a percentage of acrylamide removal from $32.96 \%$ to $54.64 \%$ by increasing the contact time from 5 to 160 minutes using $1 \mathrm{ppm}$ permanganate dose in neutral. Also acrylamide removal percentage increased in acidic medium from $87.33 \%$ to $100.00 \%$ by increasing the contact time 5 to 160 minutes. The same hydrolysis transformation carried out for acrylamide in basic medium.
\end{abstract}

Key Words: Acrylamide, LC MS/MS, potassium permanganate oxidation and Water treatment. 
J. Environ. Sci.

Institute of Environmental Studies and Research - Ain Shams University

\section{INTRODUCTION}

Acrylamide is an odorless, white crystalline solid at room temperature, with a molecular formula of $\mathrm{C}_{3} \mathrm{H}_{5} \mathrm{NO}$ and weight of 71.08. Acrylamide is readily soluble in water $\left(2155 \mathrm{~g} / \mathrm{l}\right.$ at $\left.30^{\circ} \mathrm{C}\right)$ and polar solvents (e.g. acetone, methanol, and ethanol), but not in non-polar solvents (e.g. carbon tetrachloride). Acrylamide has a density of $1.27 \mathrm{~g} / 1\left(25^{\circ} \mathrm{C}\right)$, a boiling point of $136^{\circ} \mathrm{C}$ at $3.3 \mathrm{kPa}$ and a melting point of $84-85^{\circ} \mathrm{C}$. Acrylamide contains an unsaturated amide system that reacts with nucleophilic compounds via a Michael addition. The major site of reaction is sulfydrl groups contained on proteins and amino acids (JIFSAN, 2002).

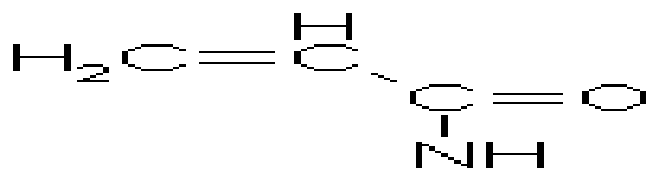

Figure (1): Chemical structure of acrylamide

Acrylamide is the main monomer of polyacrylamides that are used for the flocculation of suspended material in wastewater treatment plants. The principal source of acrylamide in the environment is the release of residual monomers from polyacrylamide flocculants. Polyacrylamide is used in many products and activities: grout, cement, drinking water and wastewater treatment, pesticides, food manufacturing (WHO, 2011), crude oil production, coatings for home appliances, building materials, automotive parts, explosives, adhesives, printing inks, adhesive tapes, and latex (Togola et al., 2015). 
Presence of acrylamide pollutant in raw water in Egypt may be considered to be one of the most serious problems for human health and living organisms. Acrylamide is classified as a "probable human carcinogen" by IARC, and has also been shown to be a neurotoxic agent in animals and humans (IARC, 1994; Friedman and Mottram 2005).

Based principally upon the weight-of-evidences assessments of several international and national agencies (US EPA, 2001; EURAR, 2002; NICNAS, 2002; NTP, 2005), a critical effect for characterization of risk to human for acrylamide is carcinogenicity, for which a mode of induction involving direct interaction with genetic material cannot be precluded (EURAR, 2002; FAO/WHO, 2006).

As a result of the harmful effect of acrylamide, many organizations tried to regulate its concentration in raw water through issuing a restricted guide lines for acrylamide.

Concerning its use in drinking water supplies, the US EPA considers that acylamide level should not exceed $0.05 \%$ at a maximum dosage of $1 \mathrm{mg} / \mathrm{L}$ and has set the maximum contaminant level (MCL) goals for acrylamide at zero (US Environmental Protection Agency, 2002).

In Europe, Registration, Evaluation, Authorization and Restriction of Chemicals (REACH) limited the Acylamide content in commercialized products to $<0.1 \%$ by weight for grouting applications after 5 November 2012 (European Parliament and European Council, 2006).

Acrylamide has also been regulated in European countries by the Drinking Water Directive that set a minimum quality requirement of $0.1 \mu \mathrm{g} / \mathrm{L}$ for water intended for human consumption (European Council, 1998). 
The European Union Cosmotics Directive stipulates a maximum residual acrylamide level of $0.1 \mathrm{mg} / \mathrm{kg}$ in body care and leave-on products and 0.5 $\mathrm{mg} / \mathrm{kg}$ in other rinse-off cosmetics products.

The Egyptian law NO.458/2007 for potable and domestic water stated that the maximum allowable level for acrylamide was $0.5 \mu \mathrm{g} / \mathrm{l}$.

Concentration levels are usually very low, and the physicochemical properties of Acylamide make this molecule difficult to quantify in natural samples. (Togola et al., 2015).

Searching for sub-ppb levels on a regular basis requires methods that are both highly sensitive and rapid. Acrylamide has been determined in environmental water samples, by direct injection (Cavalli et al., 2004; US EPA, 1994; Weideborg et al., 2001) or after a preparative step (Alpmann and Morlock, 2008; Kawata et al., 2001) for concentration, by GC-MS or GCECD, and more recently, by liquid chromatography coupled with UV (Xu et al., 2013).

It is known that potassium permanganate as strongest oxidizing agent, undergoing a three possible oxidation mechanism at different mediums as follows:

In acidic medium:

$\mathrm{MnO}_{4}{ }^{-}+8 \mathrm{H}^{+}+5 \mathrm{e}^{-} \longrightarrow \mathrm{Mn}^{2+}+4 \mathrm{H}_{2} \mathrm{O} \quad \mathrm{E}^{\mathrm{o}}=1.507 \mathrm{~V}$

In neutral or alkaline solution, the product is the brown solid, $\mathrm{MnO}$ 2:

$\mathrm{MnO}_{4}{ }^{-}+4 \mathrm{H}^{+}+3 \mathrm{e}^{-} \longrightarrow \mathrm{MnO}_{2}(\mathrm{~s})+2 \mathrm{H}_{2} \mathrm{O} \quad \mathrm{E}^{\mathbf{o}}=1.692 \mathrm{~V}$

In strongly alkaline solution, green manganate ion is produced:
$\mathrm{MnO}_{4}{ }^{-}+\mathrm{e}^{-} \longrightarrow \mathrm{MnO}_{4}{ }^{2-}$
$\mathrm{E}^{\mathrm{o}}=0.56 \mathrm{~V}$ 
The current study aimed to monitor acrylamide in drinking water treatment plants in Cairo and their corresponding raw Nile water from plant intake. Also, removal of acrylamide from aqueous solutions was carried out by using potassium permanganate oxidation.

\section{MATERIAL AND METHODS}

\section{2-1 Monitoring of acrylamide in drinking water plants in Cairo}

A survey of acrylamide concentrations was performed in raw water and treated water (drinking) of 12 water treatment plants in Cairo.

\section{a) Materials:}

Acrylamide, $99.9 \%$ purity and sodium hydroxide were purchased from sigma Aldrich. Methanol, HPLC grade and $\mathrm{HCl}, 37 \%$ from Fisher. Potassium permanganate $99.9 \%$ from Panreac. Granulated activated carbon was obtained from Chemviron-grade (207EA 12.5*40 US).

Deionized water (Type I deionized water produced from Thermosceintific deionized water system).

\section{b) Instrument:}

LC MS/MS instrument from Waters, $\mathrm{pH}$ meter (Orion 2 star, thermosceintific, USA), Gar test apparatus from Velp.

\section{c) Methods:}

Samples were collected from water treatment plants were monitored and quantified for acrylamide by (EPA 8316) using LC/MS/MS. This method is applicable for the determination of acrylamide in raw water, finished drinking water and drinking water during four seasons for different climatic conditions, using LC chromatographic equipped with MS detector with limit 
of quantification (LOQ) $0.05 \mathrm{ppb}$, measurement uncertainty (MU) 31 and recovery criteria from $85 \%$ to $115 \%$ Sample was collected from field in glass container and drinking water sample preserved by adding sodium thiosulfate to stop the reaction of chlorine. Raw water sample is filtered by membrane filter $(0.22 \mu \mathrm{m})$, and $20 \mu \mathrm{l}$ aliquot is injected (direct injection) into a reverse phase UPLC column C8 $(1.7 \mu \mathrm{m} * 2.1 * 50 \mathrm{~mm})$. Separation of the analytes is achieved using isocratic eluent conditions with a reagent bottle contain a mixture of $98 \%$ of water and $2 \%$ of methanol HPLC grade then $0.1 \%$ formic acid was added. The flow rate was $0.30 \mathrm{ml} / \mathrm{min}$. After elution from the UPLC column, acrylamide was detected by a MS/MS detector (Xevo TQ-S) using Electron-Spray-ionization (ESI) in positive mode with the following conditions:

Capillary volt $=3.2 \mathrm{KV}$ dessolvation temp. $=450 \mathrm{C}^{0}$

Desolvation $=800 \mathrm{~L} \backslash \mathrm{Hr}$ cone $=150 \mathrm{~L} \backslash \mathrm{Hr}$

Nebulizer $=7$ bar 


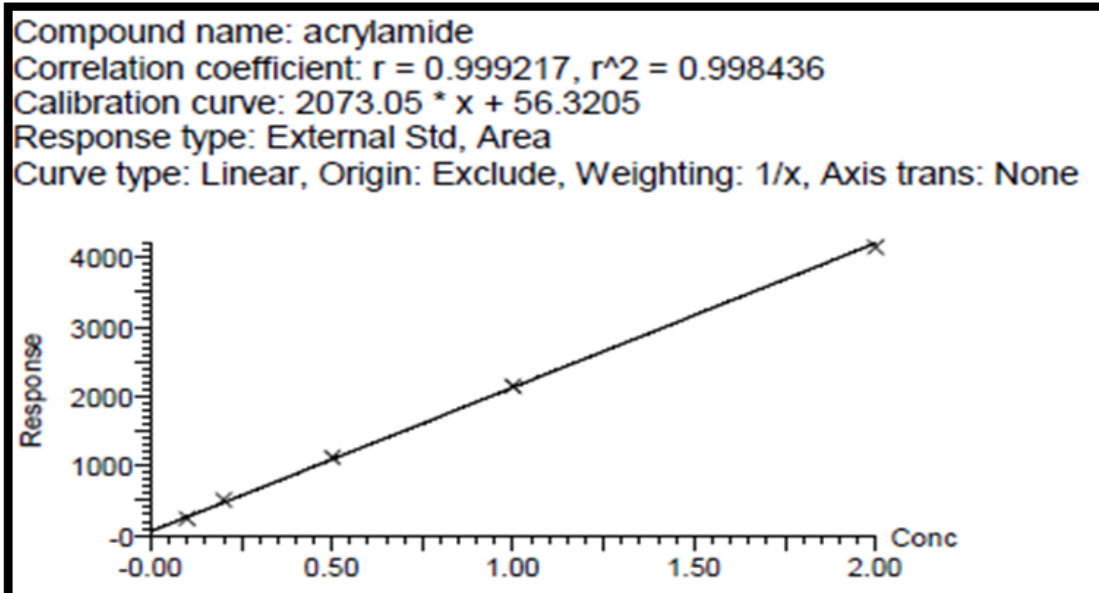

Figure (2): Calibration curve of acrylamide

Each batch (20 samples) controlled by calibration curve consist of 5 points from $0.1 \mathrm{ppb}$ to $2.00 \mathrm{ppb}$. The calibration curve was checked by Lab control sample (LCS) at concentration $0.5 \mathrm{ppb}$. Also the batch was checked by organic free water (blank sample) which its result must be less than LOQ.

\subsection{Removal of Acrylamide by potassium permanganate oxidation:}

Removal of acrylamide was performed using oxidation by potassium permanganate oxidation.

\section{Effect of $\mathrm{KMnO}_{4}$ dose:}

Each sample $(1000 \mathrm{ml})$ was spiked by acrylamide compound at concentration $50 \mathrm{ppb}$ followed by adding different dosages of $\mathrm{KMnO}_{4}(0,0.1$, $0.2,0.4,0.6,0.8,1 \mathrm{ppm})$ at different $\mathrm{pH}$ conditions $(3,7$ and 12) then samples were collected at a constant contact time 30 minute to measure the residual acrylamide concentrations by analysis on LC/MS/MS. 


\section{Effect of pH:}

Each sample $(1000 \mathrm{ml})$ was spiked by acrylamide compound at concentration $50 \mathrm{ppb}$ followed by adding constant dosages of $\mathrm{KMnO}_{4}$ at different $\mathrm{pH}$ conditions $(3,7$ and 12) then samples were collected at a constant contact time 30 minute to measure the residual acrylamide concentrations by analysis on LC/MS/MS.

\section{Effect of time:}

After sample treated by $\mathrm{KMnO}_{4} 1.00 \mathrm{ml}$ of treated at different $\mathrm{pH}$ conditions (3, 7 and 12) sample was taken at interval time (5 min., 10 min., $20 \mathrm{~min} ., 40 \mathrm{~min} ., 80 \mathrm{~min}$. and $160 \mathrm{~min}$.) to study the effect of contact time.

\section{RESULTS AND DISSCUTIONS}

\section{Monitoring of Acrylamide in twelve water plants in Cairo:}

By monitoring acrylamide pollutant in Nile water that inter the intake of water plants before the traditional treatment process and the final tap water after the traditional treatment process on winter, spring, summer and autumn during year 2014, It was found that there is a residual contamination from the acrylamide pollutant as the following table show: 
Table (2): Monitoring of acrylamide $(\mu \mathrm{g} / \mathrm{l})$ in twelve water treatment plants and their Nile in Cairo governorate during Summer \& Winter \& Spring and autumn in year 2014.

\begin{tabular}{|c|c|c|c|c|c|c|}
\hline No. & Plant Name & Sample & Winter & Spring & Summer & Autumn \\
\hline \multirow{2}{*}{1} & \multirow{2}{*}{ Tebeen } & Tap water & 0.62 & 0.15 & 0.10 & 0.00 \\
\hline & & Nile water & 0.71 & 0.20 & 0.29 & 0.11 \\
\hline \multirow{2}{*}{2} & \multirow{2}{*}{ Kafer Elw } & Tap water & 0.71 & 0.25 & 0.00 & 0.21 \\
\hline & & Nile water & 0.85 & 0.73 & 0.10 & 0.41 \\
\hline \multirow{2}{*}{3} & \multirow{2}{*}{ North Helwan } & Tap water & 0.53 & 0.34 & 0.15 & 0.20 \\
\hline & & Nile water & 0.60 & 0.45 & 0.21 & 0.32 \\
\hline \multirow{2}{*}{4} & \multirow{2}{*}{ Maadi } & Tap water & 0.47 & 0.32 & 0.17 & 0.00 \\
\hline & & Nile water & 0.67 & 0.51 & 0.34 & 0.00 \\
\hline \multirow{2}{*}{5} & \multirow{2}{*}{ Fustat } & Tap water & 0.45 & 0.40 & 0.32 & 0.00 \\
\hline & & Nile water & 0.50 & 0.52 & 0.45 & 0.00 \\
\hline \multirow{2}{*}{6} & \multirow{2}{*}{ El Roda } & Tap water & 0.39 & 0.27 & 0.00 & 0.22 \\
\hline & & Nile water & 0.45 & 0.25 & 0.00 & 0.31 \\
\hline \multirow{2}{*}{7} & \multirow{2}{*}{ Rod El Farag } & Tap water & 0.42 & 0.00 & 0.20 & 0.00 \\
\hline & & Nile water & 0.53 & 0.00 & 0.31 & 0.00 \\
\hline \multirow{2}{*}{8} & \multirow{2}{*}{ Ameria } & Tap water & 0.48 & 0.33 & 0.00 & 0.00 \\
\hline & & Nile water & 0.80 & 0.42 & 0.00 & 0.00 \\
\hline \multirow{2}{*}{9} & \multirow{2}{*}{ Mostorod } & Tap water & 0.52 & 0.31 & 0.00 & 0.00 \\
\hline & & Nile water & 0.58 & 0.43 & 0.00 & 0.00 \\
\hline \multirow{2}{*}{10} & \multirow{2}{*}{ Shoubra } & Tap water & 0.47 & 0.00 & 0.25 & 0.36 \\
\hline & & Nile water & 0.56 & 0.10 & 0.28 & 0.41 \\
\hline \multirow{2}{*}{11} & \multirow{2}{*}{ El Marg } & Tap water & 0.55 & 0.45 & 0.33 & 0.12 \\
\hline & & Nile water & 0.60 & 0.51 & 0.40 & 0.20 \\
\hline \multirow{2}{*}{12} & \multirow{2}{*}{ Obour } & Tap water & 0.67 & 0.16 & 0.00 & 0.26 \\
\hline & & Nile water & 0.81 & 0.23 & 0.00 & 0.34 \\
\hline
\end{tabular}


There are some water treatment plants results for acrylamide like Tebeen, Kafer Elw, North Helwan, Mostorod, El Marg and Obour its results were $0.62,0.71,0.53,0.52,0.55$ and $0.67 \mu \mathrm{g} / \mathrm{l}$ respectively they were higher than the permissible level of Egyptian minister of health regulations which is 0.5 $\mu \mathrm{g} / \mathrm{l}$ in Tap drinking water. It was observed that there was an industrial activity near these plants which may be responsible for such acrylamide residue contamination.

Also, the maximum results were observed during Winter this may be as a result of lower rate of biodegradation at lower temperature and this results agreed with (Weideborg et al., 2001) who stated that biodegradation is the main removal pathway for acrylamide in the environment. Acrylamide is biodegradable at aerobic conditions, acrylamide will be completely degraded within 5-10 days dependent on the temperature conditions. Low temperatures reduce the biodegradation rate. Also, it may be concentrated due to winter block (Sadda Shetwya). 


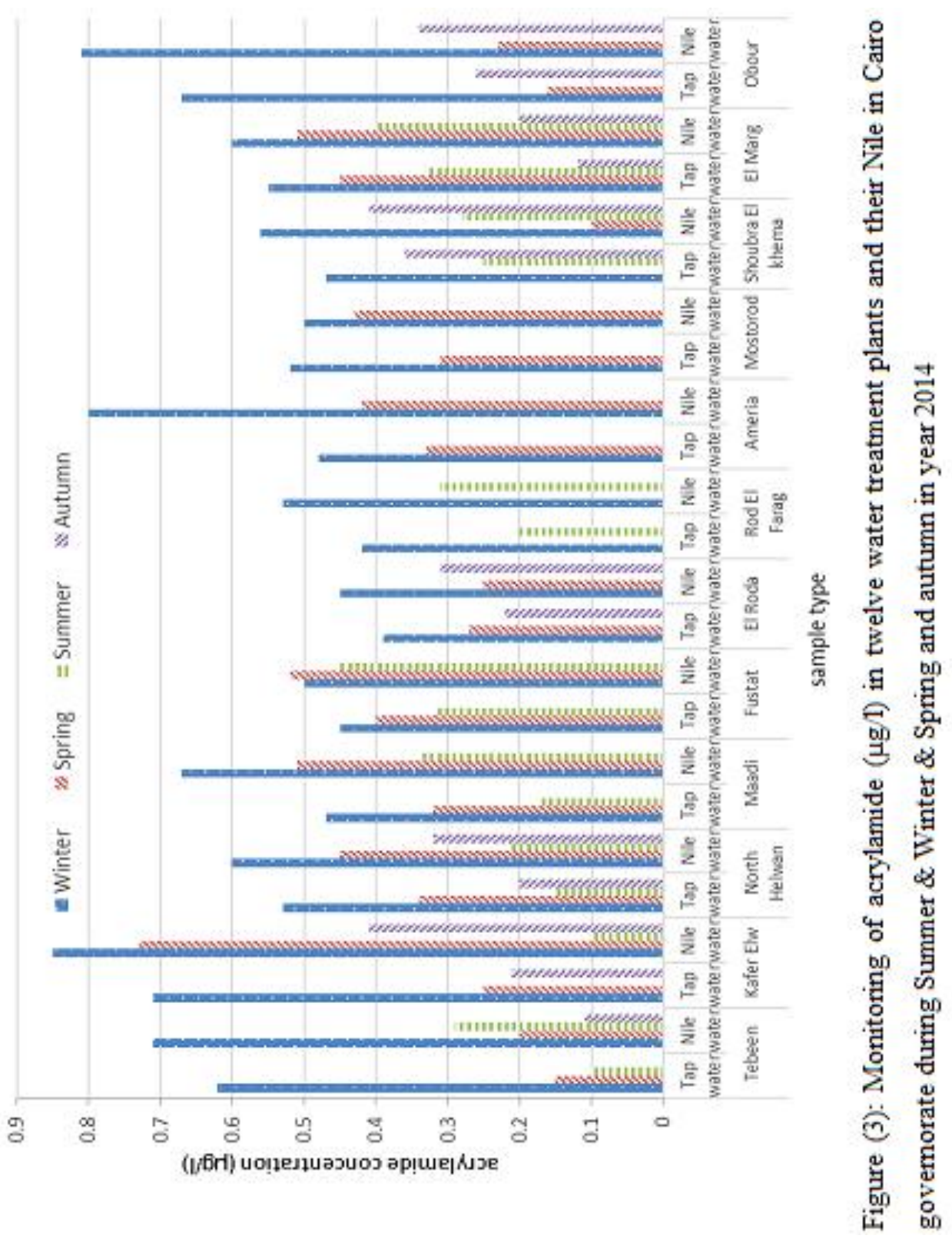

Vol.33, No.2, June, 2016 


\section{Removal of Acrylamide by potassium permanganate oxidation:}

\subsection{The effect of $\mathrm{pH}$ on acrylamide removal:}

The $\mathrm{pH}$ of the aqueous solutions plays an important role in the whole oxidation process using permanganate. The effect of $\mathrm{pH}$ upon acrylamide oxidation in solution with acrylamide concentration $50 \mu \mathrm{g} / \mathrm{l}$ by using $0.8 \mathrm{ppm}$ potassium permanganate was studied by varying the initial $\mathrm{pH}$ from 3.0-12.0. The results showed in Figure (4) indicated that the maximum acrylamide reduction of $83.74 \%, 38.57 \%$ and $100 \%$ was obtained at $\mathrm{pH} 3,7$ and 12 respectively.

The higher removal percent of acrylamide from aqueous solutions in acidic medium rather than neutral may be due to the higher oxidation power of permanganate which accept five electrons in acidic medium more than three electrons in neutral medium while the highest removal percent was achieved in basic medium could be explained on the basis of transformation into acrylic acid and ammonia due to hydrolysis which cause an absolute absence of acrylamide as shown in Figure (6) which lead to $100 \%$ percentage of acrylamide removal.

This results in agreement with the study of (Barvenik et al., 1996) who state that there are two reactive sites on acrylamide molecule. the amide group and the double bond. The amide group readily hydrolyzes in the presence of base or acid to yield acrylic acid. The rate and degree of completion of this hydrolysis is dependent on the $\mathrm{pH}$ conditions and temperature. The hydrolysis rate is somewhat higher under basic than acidic conditions, and it is quite slow at $\mathrm{pH}$ close to neutral. In addition, under 
moderate $\mathrm{pH}$ and temperature conditions a variety of compounds will react with acrylamide at the double bond to yield less toxic end products. These include strongly oxidizing agents such as permanganate and ozone yielding $\mathrm{CO}_{2}, \mathrm{H}_{2} \mathrm{O}$ and ammonia.

Weideborg et al. (2001) monitored acrylamide and methylolacrylamide concentrations as a result of using a grouting agent in drainage water from the tunnel construction of Romeriksporten project in Norway which discharged to Alna River. The use of microcements in the construction work resulted in very high $\mathrm{pH}(10-13)$ in the drainage water yielding acrylic acid as a hydrolysis product.

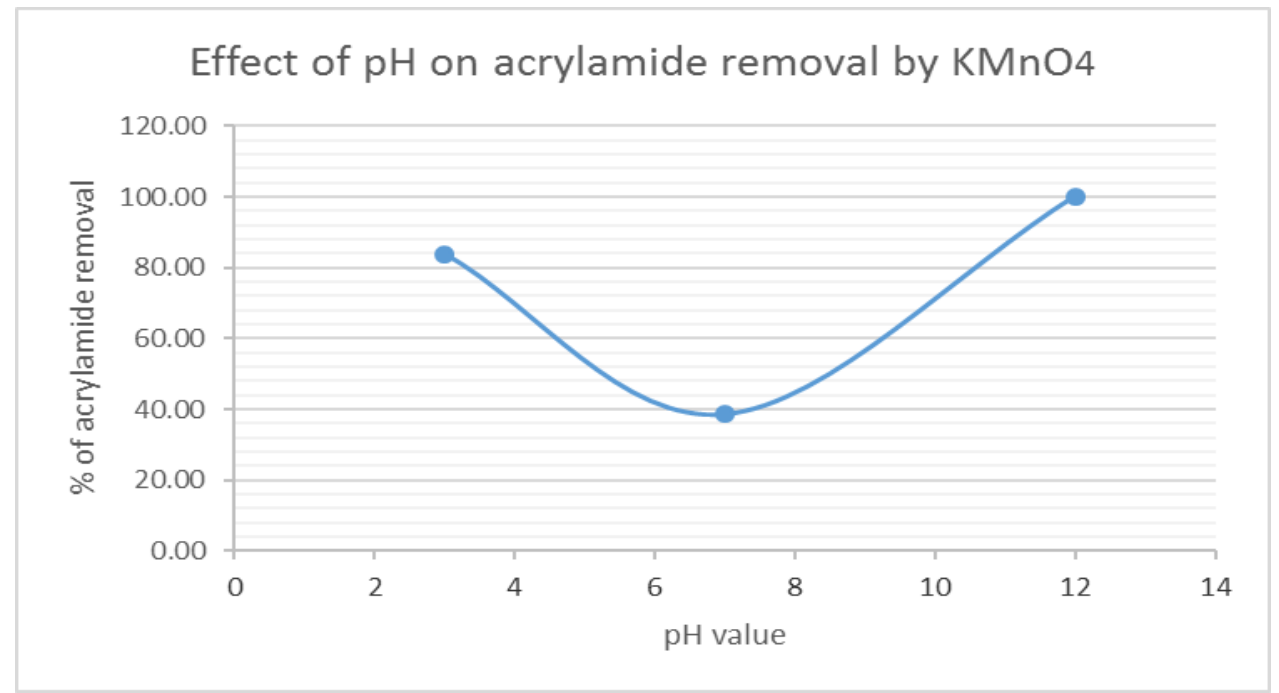

Figure (4): The effect of varying the $\mathrm{pH}$ upon \% acrylamide removal using the permanganate oxidation. 


\subsection{The effect of KMON4 dose on acrylamide removal:}

The effect of varying permanganate dose upon the acrylamide reduction in solution with acrylamide concentration $50 \mu \mathrm{g} / \mathrm{l}$ at constant contact time 30 min and different $\mathrm{pH}$ conditions is shown in Figure (5). Results indicate a good percentage of acrylamide reduction which increase with increasing the dose of $\mathrm{KMnO}_{4}$ from $13.40 \%$ to $41.40 \%$ at doses $0 . r$ to $1 \mathrm{ppm}$ respectively in neutral medium $\mathrm{pH}(7)$

Acrylamide removal percentage increased in acidic medium $\mathrm{pH}$ (3) from r 9,0 r\% to $96.67 \%$ at doses $0 . r$ to $1 \mathrm{ppm}$ respectively.

While in basic medium $\mathrm{pH}$ (12) acrylamide undergoes transformation into acrylic acid which causes an absolute absence of acrylamide as shown in figure (5) which lead to $100 \%$ percentage of acrylamide transformation.

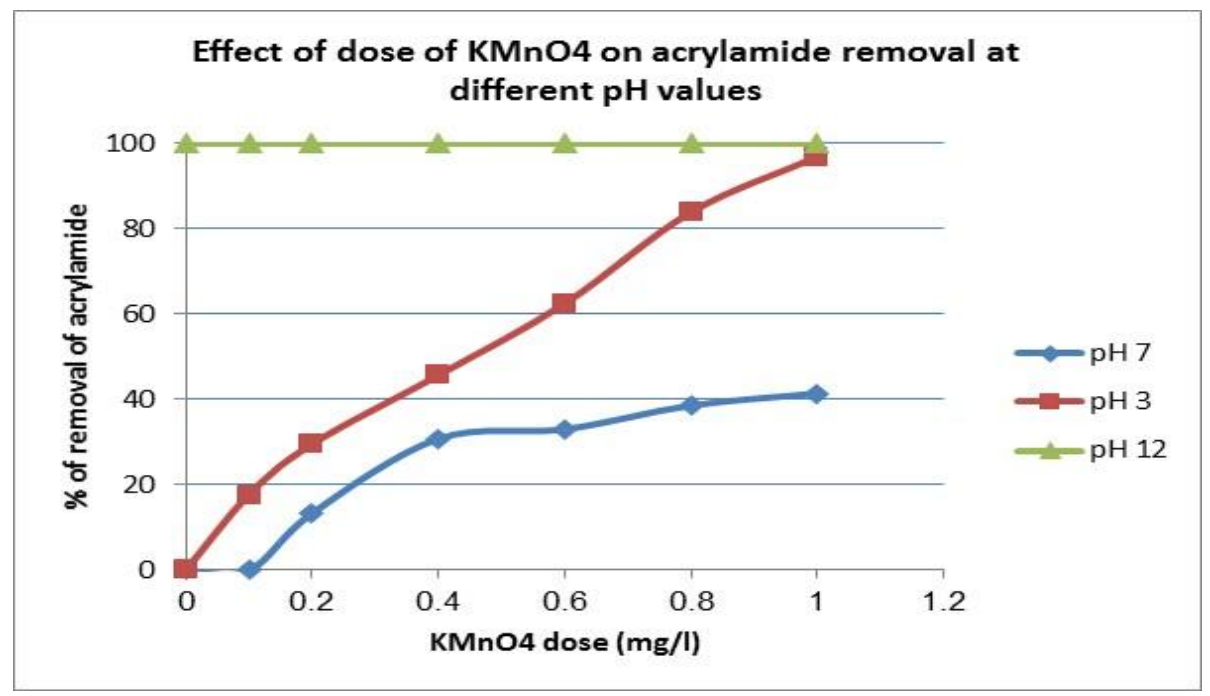

Figure (5): The effect of varying the doses upon \% acrylamide removal using the permanganate oxidation. 

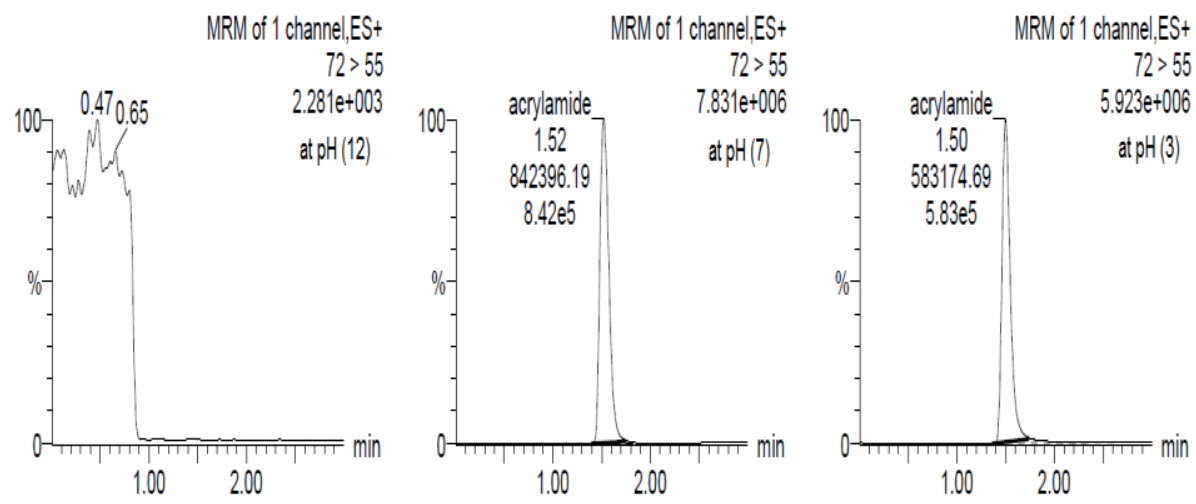

Figure (6): Chromatogram of acrylamide peak on different $\mathrm{pH}$ conditions.

\subsection{The effect of contact time on acrylamide removal:}

The effect of varying contact time upon the acrylamide reduction in solution with acrylamide concentration $50 \mu \mathrm{g} / \mathrm{l}$ is shown in Figure (7). The results indicate a percentage of acrylamide reduction of 32.96 at a contact time 5 minutes and increased to $54.64 \%$ at a contact time 160 minutes using 1 ppm permanganate dose at $\mathrm{pH}(7)$.

Acrylamide removal percentage increased in acidic medium $\mathrm{pH}$ (3) from $87.33 \%$ at a contact time 5 minutes and increased as the contact time increased to $100.00 \%$ at a contact time 120 minutes using 1 ppm permanganate dose. While in basic medium $\mathrm{pH}$ (12) absence of acrylamide due to transformation into acrylic acid as mentioned before. 
J. Environ. Sci.

Institute of Environmental Studies and Research - Ain Shams University

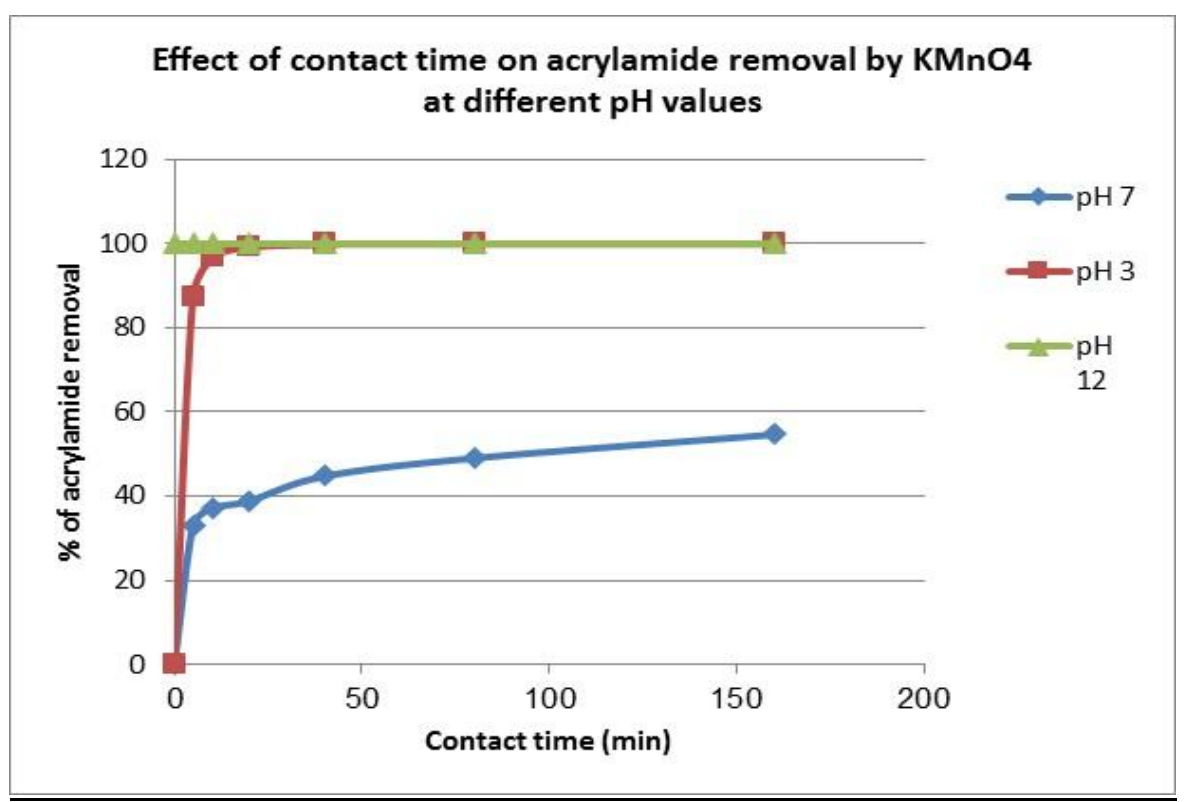

Figure (7): The effect of contact time upon \% acrylamide removal.

\section{CONCLUSION}

In the current work, monitoring of acrylamide in drinking water treatment plants in Cairo and their corresponding raw Nile water from plant intake was carried out. Also, the removal of acrylamide pollutant from aqueous solution using oxidation process with potassium permanganate was investigated. Optimization studies were carried out through several jar tests to determine the optimum $\mathrm{pH}$, dose and contact time for acrylamide removal using permanganate oxidation. The experimental data indicated a good percentage of acrylamide removal by potassium permanganate increased from $13.40 \%$ to $41.40 \%$ by increasing the dose from 0.2 to $1 \mathrm{ppm}$ respectively in neutral medium. Also acrylamide removal percentage increased in acidic 
medium from $29.52 \%$ to $96.67 \%$ at doses 0.2 to $1 \mathrm{ppm}$ respectively. While in basic medium absence of acrylamide due to transformation into acrylic acid. On the other hand, results indicate a percentage of acrylamide removal from $32.96 \%$ to $54.64 \%$ by increasing the contact time from 5 to 160 minutes using $1 \mathrm{ppm}$ permanganate dose in neutral. Also acrylamide removal percentage increased in acidic medium from $87.33 \%$ to $100.00 \%$ by increasing the contact time 5 and 160 minutes. The same transformation carried out for acrylamide in basic medium.

\section{REFERENCES}

Alpmann, A. \& Morlock, G. (2008): Rapid and sensitive determination of acrylamide in drinking water by planar chromatography and fluorescence detection after derivatization with dansulfinic acid. J Sep Sci, 31(1), 71-77.

Barvenik, F. W., Sojka, R.E., Lentz, R. D., Andrawes, F. F. \& Messner, L. S. (1996): Fate of acrylamide monomer following application of polyacrylamide to cropland. In: Sojka, R.E. and Lentz, R.D. (eds.) Managing irrigation-induced erosion and infiltration with polyacrylamide. University of Idaho Miscellaneous, Publication No. 101-96, pp. 103-110.

Cavalli, S., Polesello, S. \& Saccani, G. (2004): Determination of acrylamide in drinking water by large-volume direct injection and ionexclusion chromatography-mass spectrometry. J Chromatogr A, 1039(1-2), 155-159.

European Council, (1998): Directive 98/83/EC of 3 November 1998 on the quality of water intended for human consumption. In: Union E. Official Journal of the European Communities, Brussels.

European Parliament, European Council (2006): Registration, Evaluation, Authorisation and Restriction of Chemicals (REACH), establishing a European Chemicals Agency. No 1907/2006. 
European Union Risk Assessment Report (EURAR), (2002): CAS: 79-06-1. Acrylamide. Luxembourg: Office for Official Publications of the European Communities. Report No.: On the cover, European Commission Joint Research Centre. EUR 19835 EN. p. 221.

FAO/WHO, (2004): Discussion paper on acrylamide. Thirty-sixth Session Rotterdam, The Netherlands, 22-26 March.

Friedman, M. \& Mottram, D. (2005): Chemistry and safety of acrylamide in food. Advances in Experimental Medicine and Biology, v. 561, Springer Science \& Business Media, p. 448.

Harris, D. C. (2010): Quantitative chemical analysis, Eighth Edition, Clancy Marshall, W. H. Freeman and Company, p. 349.

IARC, (1994): Acrylamide, In IARC monographs on the evaluation of carcinogenic risks to humans, some industrial chemicals, WHO, Geneva, Switzerland. 60, 389-433.

JIFSAN/NCFST Workshop on Acrylamide in Food, (2002): Overview of Acrylamide Toxicity and Metabolism, ILSI North America (ILSI N.A.) Project Committee on Acrylamide, Chicago, USA.

Kawata, K., Ibaraki, T., Tanabe, A., Yagoh, H., Shinoda, A., Suzuki, H. \& Yasuhara, A. (2001): Gas chromatographic-mass spectrometric determination of hydrophilic compounds in environmental water by solid-phase extraction with activated carbon fiber felt. $\mathbf{J}$. Chromatogr. A. 911(1), 75-83.

National Industrial Chemicals Notification and Assessment Scheme (NICNAS), (2002): Acrylamide. Priority Existing Chemical Assessment Report No. 23. Commonwealth of Australia.

National Toxicology Program (US) (NTP), (2005). NTP-CERHR monograph on the potential human reproductive and developmental effects of acrylamide. Research Triangle Park (NC). US Department of Health and Human Services, National Toxicology Program. Center for the Evaluation of Risks to Human Reproduction. NIH Publication No. 05-4472. 
Togola, A., Coureau, C., Guezennec, A., Touze, S. (2015): A sensitive analytical procedure for monitoring acrylamide in environmental water samples by offline SPE-UPLC/MS/MS. Environ Sci Pollut Res, 22:6407-6413.

US Environmental Protection Agency (1994): Acrylamide, acrylonitrile and acrolein by high performance liquid chromatography. Method 8316. Cincinnati, USA.

US Environmental Protection Agency (2002): National primary drinking water regulation. Washington D.C.

US Environmental Protection Agency (US EPA), (2001): Acrylamide (CASRN 79-06-1). Washington D.C.

Weideborg, M., Kallqvist, T., Odegard, K. E., Sverdrup, L. E. \& Vik, E. A. (2001): Environmental risk assessment of acrylamide and methylolacrylamide from a grouting agent used in the tunnel construction of Romeriksporten, Norway.Water Res 35(11), 26452652.

WHO, (2011): Acrylamide in drinking-water. Background document for development of WHO guidelines for drinking-water quality. Vol WHO/SDE/WSH/03.04/71/rev1, WHO edn.

Xu, L. H., Qiao, X. G., Ma, Y., Zhang, X., \& Xu, Z. X., (2013): Preparation of a hydrophilic molecularly imprinted polymer and its application in solid-phase extraction to determine of trace acrylamide in foods coupled with high-performance liquid chromatography. Food Anal Methods, 6(3), 838-844. 


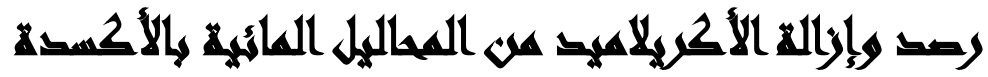

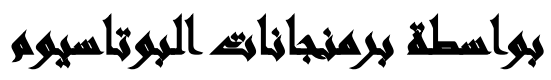

\section{$[r]$}

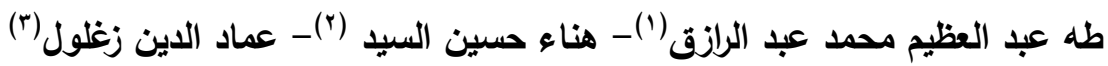



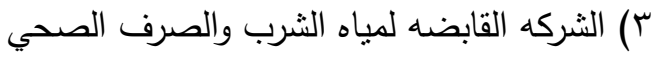

\section{المستخلم}

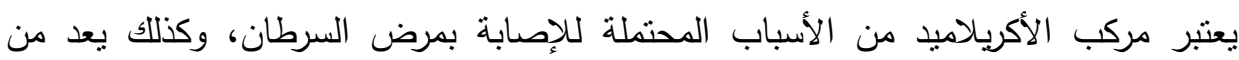

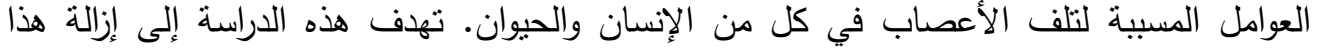

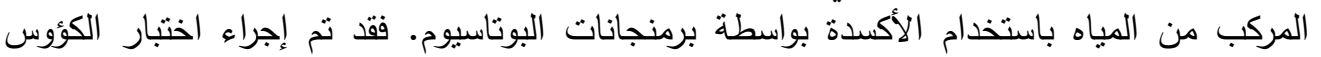

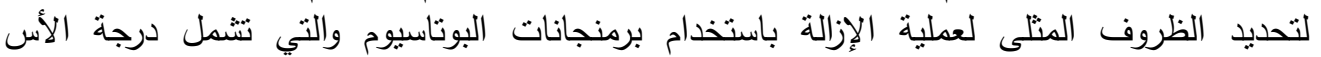

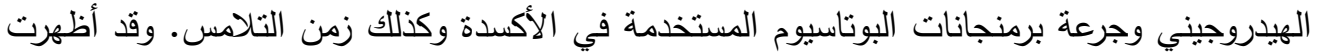



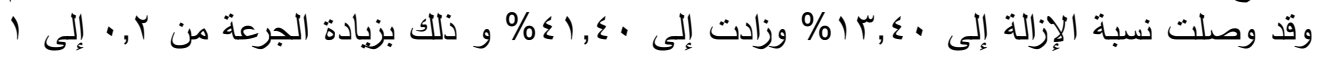

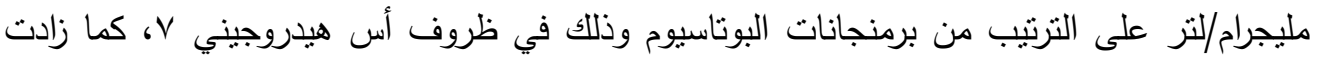

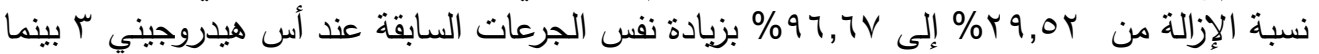

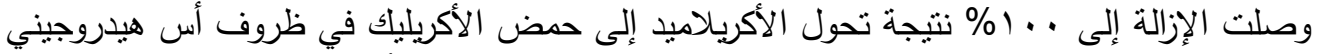

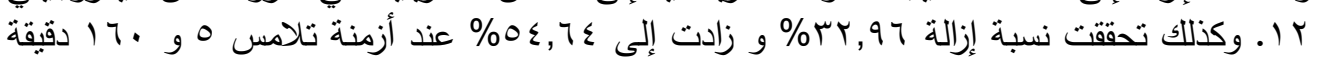

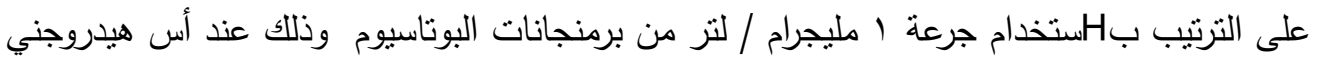

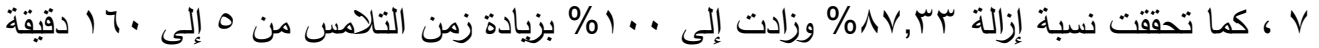
في ظروف أس هيدروجيني r. 